\title{
SÃO PAULO E OS SIGNOS DA MODERNIDADE: A QUESTÃO DA SEGURANÇA PRIVADA $\left(^{*}\right)$
}

\author{
Odette Carvalho de Lima Seabra(**)
}

Há muitos e variados signos da modernidade inscritos no espaço da metrópole que, como sinais, como marcas de um movimento acelerado de coisas, de pessoas, de dinheiro, de decisões, de desejos, de imagens... são cristalizações de um modo de viver, de um modo de ser metropolitano, na periferia do terceiro mundo. O núcleo e a substância desse movimento está na mundialização da produção, resultado estratégico da atuação das empresas multinacionais e das determinações políticas e econômicas dos organismos financeiros internacionais: 0 Fundo Monetário Internacional e o Banco Mundial.

A empresa multinacional, forma atualizada dos trustes e dos cartéis do século XIX, redefinindo sem cessar a sua base técnica e o seu patamar de produtividade em escala mundial, atua no sentido da "uniformização" por cima do que a História e a Cultura produziram como diferenças. Assim, o processo de mundialização, apesar de criar contradições com o Estado-Nação, acaba por capturá-lo, esfumando os interesses divergentes na medida que garante a reprodução das elites enquanto elites. $O$ Brasil e o Chile oferecem bons exemplos.

De tal forma que as adequações e as contradições que se multiplicam. e afloram no espaço metropolitano, nas suas cristalizações, se afirmam no mundo ganhando existência no cotidiano da vida urbana.

Em São Paulo os pingentes dos trens e dos ônibus suburbanos; as esquinas de mercado (como o cruzamento da Av. Brasil com a Av. Rebouças). A super exploração dos que trabalham contrastando com o enorme exército de desempregados; a prostituição de adolecentes; os sem casa; os sem teto.... os sem nada, crianças, jovens, adultos e velhos.... todos indicam, sinalizam as dimensões do movimento da modernidade.
As metrópoles guardam a expressão estética desta contemporaneidade que em nada está melhor traduzida do que na arquitetura como expressão formal e material destes tempos. As vias de trânsito rápido se entrecruzando, os estacionamentos cada vez maiores e mais numerosos; as soluções urbanísticas ligadas à moradia... enfim, tudo está revestido de extrema complexidade e tem um sentido de ser metropolitano, o sentido de ser rápido, e se possível, descartável!...

O maior dos signos da modernidade contemporânea é, sem dúvida, o da arquitetura bancária onde se combinam engenho e arte para produzir as "catedrais" do nosso tempo!

O tempo do dinheiro; o tempo no qual o sentido do ter sobrepujou todos os sentidos; o tempo da simulação consentida.

Mas, é a partir de uma reflexão clássica sobre o processo de urbanização brasileira que abordo a questão da segurança privada, entendendo-a como uma das evidências que qualifica e atualiza a problemática urbana.

Entendo que as relações entre Estado e urbano no Brasil constituem as premissas, históricas e lógicas, para avançar na compreensão dos atuais processos de urbanização. Insisto nas relações que colocam o Estado como provedor de condições gerais sociais da produção e reprodução social. No Estado como centro de decisões, de opções, e de gestão do excedente econômico. E também

(") Trabalho apresentado no II Seminário Latino Americano de Geografia Crítica - Buenos Aires - 1990

(**) Professora do Departamento de Geografia da FFLCH/USP. 
considero, desde logo, que os moldes como se reproduz a força de trabalho no Brasil, tanto a força de trabalho ativa como a virtual, é resultante de políticas de longo prazo que visaram:

a - determinação de parâmetros nacionais para reprodução da força de trabalho ( criação de salário mínimo nacional 1930)

b - estabelecimento de políticas fiscais que favoreceram o comércio inter regional (abolição de tarifas aduaneiras entre unidades político-administrativas federadas)

c - implementação de políticas regionais de desenvolvimento com a criação de órgãos regionais de planejamento (criação da SUDENE, p.ex.)

d - políticas de expansão da fronteira agrícola com a ocupação do centro - oeste e norte do território nacional

e - vasto programa de produção de infra-estrutura viária, reaparelhamento dos portos, construção de aeroportos...

f - as políticas nacionais de desenvolvimento urbano dos anos 70 com a criação da Comissão Nacional de Desenvolvimento urbano e institucionalização das Regiões Metropolitanas.

Em suma, pode-se dizer que a atuação do Estado tem visado integrar o território nacional na perspectiva da constituição de um mercado de trabalho unificado, propiciando desenvolvimento em extensão e em profundidade das relações capitalistas no Brasil. Como decorrência, em todo território nacional ampliam-se os circuitos das mercadorias.

O desdobramento social de tais políticas pode ser analisado no problema das migrações nacionais, da concentração da renda nacional $e$, sobretudo, nas difíceis condições de vida para mais de noventa por cento dos brasileiros; nesse contexto é que surge a questão metropolitana como problema nacional.
Veja-se: quarenta milhões de brasileiros não moram onde nasceram. Perto de vinte milhōes estão em trânsito.

Quanto à concentração de renda hoje, pode-se concluir que os pobres do Brasil são muito mais pobres, até mesmo, que pobres da India.

No Brasil $20 \%$ dos mais pobres têm $2 \%$ da renda nacional

$\mathrm{Na}$ India $20 \%$ dos mais pobres têm $7 \%$ da renda nacional

No Brasil $20 \%$ dos mais ricos têm $66 \%$ da renda nacional

$\mathrm{Na}$ India $20 \%$ dos mais ricos têm $49 \%$ da renda nacional

População: Brasil 1990 - 140.000.000 (estimativa) India $1990-800.000 .000$

A cidade, hoje no Brasil, se constitui no locus principal de reprodução da força de trabalho, já que as migrações nacionais acabaram por concentrar perto de $75 \%$ da população brasileira em cidades. Desse processo o fenômeno metropolitano é sua expressão mais cabal.

Pode-se dizer que há um movimento geral de riquezas e de pessoas por todo o território nacional, e que nesse movimento as metrópoles nacionais vão sendo transformadas. Tanto que as funções mais essenciais da cidade como lugar da cooperação, das condições gerais sociais da produção e da reprodução social estão sendo ameaçadas pela magnitude dos processos que nelas se desenrolam.

Os anos setenta marcaram uma mudança de qualidade na urbanização brasileira. A partir dessa década o fenômeno metropolitano parece explodir deixando, cada vez mais, expostos os limites reais à vida com urbanidade ou a vida com humanidade, já que a humanidade possível se coloca em níveis muito baixos.

Destaco no contexto da problemática metropolitana, a questão da segurança; mais precisamente da segurança expressa nos serviços privados de guarda e vigilância, pois na materialidade urbana estão praças e jardins cercados, 
Igrejas cercadas, muros altos, aliás cada vez mais altos; muros que protegem mas isolam; grades em profusão, lanças em profusão. Alarmes, Walk-toks, inter-fones, cirenes, cabines de vigilância, bairros inteiros cercados, guardas armados, cachorros e vigilantes.... É a síndrome do medo que suporta como contrapartida a indústria da segurança.

Em princípio vale assinalar que a arquitetura recente de São Paulo expõe na forma de um "urbanismo policial" nada mais que uma adequação de uma dada forma a um dado conteúdo, produzindo em certos casos um urbanismo que trata de cuidar do medo, que ratifica como "isolamento por necessidade" o caráter segregativo da sociedade e a dimensão da vida privada calcada num tal grau de individualismo que sufoca toda e qualquer individualidade. Trata-se de um processo que comporta mais de uma resposta do ponto de vista do urbanismo destinado a produzir habitações de renda alta:

a) os condomínios fechados nas franjas da metrópole, do tipo Alfaville, chácara Flora, Tamboré.

b) edificações do tipo "casas térreas", como unidades com guaritas e guardas armados, cachorros treinados, isoladas em bairros inscritos na textura da cidade.

c) edifícios residenciais de alto luxo; prédios nobres com apartamentos que chegam a ter $1.200 \mathrm{~m}^{2} \mathrm{com}$ piscinas, jardins suspensos, heliportos.

As separações, as fragmentações da vida, tal como ocorrem nesta sociedade desde as fases mais incipientes do industrialismo, sobressaem agora, perpassadas pela síndrome do medo, e acabam por justificar, por exigir, os esquemas de guarda e vigilância e os equipamentos eletrônicos de segurança, respondendo às necessidades postas pela vida social. Neste urbanismo ao qual me refiro está apenas uma evidência do processo geral de urbanização da sociedade brasileira, pois sobressai também no quadro edificado habitações simples e modestas gradeadas em todas as suas aberturas exteriores. São grades e lanças de todos os tipos e tamanhos.

Assim, tanto quanto o urbanismo ratifica a segregação, o medo difuso sedimenta todas as formas de separações, isolamentos, estranhamentos e constrangimentos. Foi então no bojo de uma questão da violência urbana, cujo cerne está na extrema pobreza de milhões de habitantes da metrópole, que bairros de alto luxo e mesmo bairros de classes médias viraram, num certo sentido, verdadeiras fortificações.

No interior dessa problemática começaram ser organizados serviços de guarda e vigilância que empregam hoje em São Paulo entre 80.000 a 100.000 pessoas, com registro em carteira, (Informação obtida junto à Polícia Federal). Oficiosamente, fala-se também de mais 50.000 empregos que existem à margem da legislação.

A legislação normativa sobre o assunto data de 1983 e pescreve, sobre os quadros de pessoal, que todo vigilante tem necessariamente que ser preparado para suas funções, em cursos especialmente criados para esse fim. Há, em São Paulo, 23 cursos de formação de guardas e vigilantes; cursos que são inspecionados pela Polícia Federal. Exige-se dos candidatos diploma de curso primário.

Em quinze dias, período de duração dos cursos, estão os alunos habilitados para o trabalho. Os cursos são de treinamento para uso de armas de fogo. Os instrutores, conforme prevê a legislação, são indivíduos que legalmente foram habilitados ao uso de armas. Por isso nas escolas funcionam como instrutores muitos militares reformados.

Quanto ao perfil desses trabalhadores sabe-se que entre eles predominam nordestinos com idade entre 20 a 25 anos.

São no total 105 empresas organizadas que vendem guarda e vigilância na cidade de São Paulo. Excluídas as maiores que transportam dinheiro para o sistema bancário a Brinks, Transvalor e Protege. Dentre as 105 , há quatro consideradas grandes, sendo que a maior emprega 10.000 pessoas e tem sua própria escola preparatória com sede em Guarulhos.

Quanto às perspectivas de ganho nestas atividades, foi possível saber que uma empresa considerada pequena com 238 empregados podia faturar entre 3 a 4 milhões de cruzeiros mensais (setembro de 1990).

Afinal de que fenômeno se trata? É isto da natureza da urbanização capitalista? 
Nesse sentido vale assinalar que nasceu e se institucionaliza rapidamente em São Paulo uma indústria da segurança que se realiza, do ponto de vista econômico, como atividade privada, de guarda e vigilância. $O$ problema a ser compreendido talvez seja:

1) de verificar como no Estado, entendido aqui como esfera de administração pública destinada a cuidar da segurança pública, foi sendo aberta uma lacuna para privatização dessas funções;

2) como nasceu e desenvolveu-se a necessidade social da segurança privada.

Em princípio cabe indicar que no capítulo referente à segurança o poder público jamais deixou de investir, e que nos últimos 8 a 10 anos o poder executivo tem sempre cuidado de aumentar o efetivo policial e aumentar o número de viaturas policiais. $\mathrm{E}$ por outro lado, do ponto de vista da demanda social, a necessidade mais premente que as pesquisas de opiniōes colocam para a administração pública tem sido também a necessidade de segurança. Há por isso um aparente paradoxo. Enquanto a segurança pública e a segurança privada aumentam, aumenta a insegurança que constitui a própria demanda por segurança.

Trata-se de um processo que parece explodir a cidade. O que implicaria também na implosão do poder, pois que no limite diante da morte a vida se eleva. Não se trata de um pensamento romântico. Veja-se algumas das tragédias que revelam esta implosão: cinquenta e três milhões de brasileiros passam fome; milhões são analfabetos; há milhões de crianças abandonadas pelas ruas, há os sem terra, os sem tetos... Do que resulta um confronto maior do que o Estado presumidamente é capaz de suportar, tanto que no Brasil há correntes de opinião que se debatem pela pena de morte.

No entanto, em meio ao que parece uma "guerra civil" a vida se eleva lá nos subterrâneos pela organização nacional dos meninos de rua, organização nacional dos sem terra e dos sem tetos.

Arrisco-me a interpretar o problema que comecei discutir, a partir da materialidade urbana, colocando-o como problema que atinge o psiquismo social que agora está perpassado pelo medo, como sentimento que cresce na razão inversa ao prazer da vida social, do qual o urbanismo policial é apenas forma. O conteúdo do drama está diariamente nas manchetes dos jornais metropolitanos. De um drama cujos atores reais e virtuais não são apenas os guardas e vigilantes, mas todos os habitantes da metrópole; resta para cada um a incógnita de saber-se como vítima ou como algoz.

\section{RÉSUMÉ}

Ce bref essai indique, comme "signe" de la modernité, la materérialité inscrite dans l'espace metropolitain de São Paulo à titae de securité privée. Il indique aussi quelques réponses de l'urbanisme à la violence urbaine que se répand. 